\title{
A CHEGADA DO OUTRO EM BARRA DO OURO - TO E A EXPULSÃO DAS COMUNIDADES CAMPONESAS NA GLEBA TAUÁ PARA A EXPANSÃO DO AGRONEGÓCIO
}

\author{
THE ARRIVAL OF THE OTHER IN BARRA DO OURO - TO AND THE EXPULSION \\ OF THE PEASANT COMMUNITIES IN GLEBA TAUÁ FOR THE EXPANSION OF \\ AGRIBUSINESS
}
LA LLEGADA DEL OTRO A BARRA DO OURO - TO Y LA EXPULSIÓN DE LAS COMUNIDADES CAMPESINAS EN GLEBA TAUÁ PARA LA EXPANSIÓN DE LA AGRICULTURA AGROINDUSTRIAL

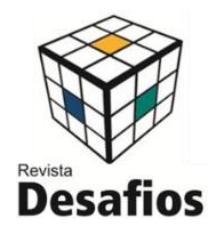

\section{Hudson Nascimento de Sousa Filho ${ }^{* 1}$, Alberto Pereira Lopes².}

${ }^{1}$ Laboratório de Estudos Agrários e Direitos Humanos (LEADH), Curso de Licenciatura em Geografia, Universidade Federal do Tocantins, Araguaína, Brasil.

${ }^{2}$ Laboratório de Estudos Agrários e Direitos Humanos (LEADH), Curso de Licenciatura em Geografia, Universidade Federal do Tocantins, Araguaína, Brasil.

*Correspondência: Laboratório de Estudos Agrários e Direitos Humanos (LEADH), Universidade Federal do Tocantins, Avenida Paraguai (esquina com a Rua Uxiramas), Araguaína, Tocantins, Brasil. CEP:77.824-838. Email: hnascimento329@gmail.com.

Artigo recebido em 29/03/2020 aprovado em 28/05/2020 publicado em 30/10/2020.

\section{RESUMO}

Ressalta-se que o presente trabalho acadêmico foi realizado com objetivos de: analisar o conflito e a conflitualidade na Gleba Tauá, município de Barra do Ouro, norte do Tocantins, a respeito da expulsão de posseiras(os) que vivem há mais de 60 anos na região para ocupar os grileiros produtores de soja, apontando ainda as formas de vida das famílias e de uso reciproco da terra que se contrapõem às formas destrutivas das quais o capital se apropria para utilização do mesmo espaço geográfico. Fazendo desta pesquisa um construto de reflexões materialistas históricas e dialéticas com ênfase no acontecer político expresso pelo movimento recorrente da relação entre estrutura e dinâmica do conflito e da conflitualidade ocorrente na gleba. Questões oriundas devido expansão da territorialização do capital do agronegócio sobre os territórios dos tradicionais povos viventes no estado tocantinense, encontrando-se em aglomerados de exclusão reterritorializados de forma precária nesse espaço geográfico. Mas, entretanto, re-existes na medida em que fazem da agricultura familiar seu modo de existência e resistência à frente pioneira da economia agroindustrial moderna.

Palavras-chave: Territórios Tradicionais, Conflitualidade, Agronegócio.

\section{ABSTRACT}

It is noteworthy that this academic work was carried out with the following objectives: to analyze the conflict and the conflict in Gleba Tauá, municipality of Barra do Ouro, north of Tocantins, with respect to the expulsion of the illegal occupants (os) who have lived for over 60 years in the region to occupy soybean grileiros, also pointing out the ways of life of families and the reciprocal use of land that opposes the destructive ways in which capital appropriates the use of the same geographical space. Turning this research into a construction of historical and dialectical materialistic reflections with an emphasis on the political event expressed by the recurrent movement of the relationship between the structure and dynamics of conflict and the conflict that occurs on earth. Issues that arise due to the expansion of the territorialization of the agribusiness capital over the territories of traditional peoples living in the state of Tocantins, meeting in territories precariously excluded in this geographic space. However, in the meantime, they re-exist to the extent that they make family farming their mode of existence and resistance to the pioneering front of the modern agro-industrial economy.

Keywords: Traditional Territories, Conflict, Agribusiness. 


\section{RESUMEN}

Es de destacar que el presente trabajo académico se llevó a cabo con los siguientes objetivos: analizar el conflicto y el conflicto en Gleba Tauá, municipio de Barra do Ouro, norte de Tocantins, con respecto a la expulsión de los ocupantes ilegales (os) que han vivido durante más de 60 años en la región para ocupar los grileiros de soja, señalando también las formas de vida de las familias y el uso recíproco de la tierra que se opone a las formas destructivas en que el capital se apropia del uso del mismo espacio geográfico. Convirtiendo esta investigación en una construcción de reflexiones materialistas históricas y dialécticas con énfasis en el acontecimiento político expresado por el movimiento recurrente de la relación entre la estructura y la dinámica del conflicto y el conflicto que ocurre en la tierra. Cuestiones que surgen debido a la expansión de la territorialización del capital del agronegocio sobre los territorios de los pueblos tradicionales que viven en el estado de Tocantins, que se encuentran en grupos de exclusión preterritoriales re-territorializados en este espacio geográfico. Sin embargo, mientras tanto, vuelven a existir en la medida en que hacen de la agricultura familiar su modo de existencia y resistencia al frente pionero de la economía agroindustrial moderna.

Descriptores: Territorios Tradicionales, Conflicto, Agronegocios.

\section{INTRODUÇÃO}

Uma análise contextual do território Gleba Tauá tanto em sua concepção material quanto relacional - estruturada com nossa compreensão aos diferentes (hegemônicos e hegemonizados) tipos de uso funcional do território - permite-nos entender a atual configuração espacial do campo tocantinense como espaço de conflitualidades que não negam a condição de (re)territorialização precária em que vivem cotidianamente, a todo tempo e em diferentes temporalidades, os posseiros moradores da gleba. Sofrendo ameaças e diversas formas de violência física às simbólicas como apresenta-se no discorrer da pesquisa. Não obstante, discute-se a respeito dos mandos e desmandos - que trucidam $^{1}$ a cultura campesina tocantinense - do grande latifundiário sendo na verdade mais um dos muitos grileiros produtores de soja instalados na região.

Dessa forma, este trabalho trata-se de uma pesquisa construída com apoio do Conselho Nacional de Desenvolvimento da Pesquisa (CNPq), a partir de estudos empregados no Programa Institucional de Bolsas de Iniciação Científica (PIBIC), da Universidade Federal do Tocantins Campus de Araguaína. Buscando cumprir os objetivos de: (1) analisar o conflito e a conflitualidade na Gleba Tauá, município de Barra do Ouro, norte do Tocantins, a respeito da expulsão de posseiras(os) que vivem há mais de 60 anos na região para ocupar os grileiros produtores de soja; (2) identificar as famílias que vivem sob as ameaças e despejos violentos dos "mandados" que trabalham para os donos do agronegócio; e (3) Analisar as formas de vida das famílias e de uso reciproco da terra que se contrapõem as formas destrutivas ao qual o capital se apropria para utilização do espaço geográfico ao mesmo tempo em que expropria diferentes territórios tradicionais no Brasil.

De modo que a totalidade relacional existente na essência conflituosa do território Gleba Tauá, em Barra do Ouro-TO ao qual encontramos famílias resistindo à frente pioneira e territorialização do capital do agronegócio. Nesse sentido, por meio de uma apreensão dialética das relações socioespaciais, fazendo-se necessário compreender que a estrutura do problema aqui estudado situa-se consecutivamente na materialização relacional de poderes no espaço agrário do norte tocantinense ao ponto que a dinâmica desta questão está expressa de modo impar no conflito - da conflitualidade - à resistência dos povos que (re)constroem suas identidades sob a situação de fronteira.

Destarte, para essa pesquisa foi de suma importante buscar geograficamente 
[...] descobrir as relações entre os processos ocorrentes nas totalidades constitutivas tomadas na sua diversidade e entre elas e a totalidade inclusiva que é a sociedade burguesa. Tais relações nunca são diretas; elas são mediadas não apenas pelos distintos níveis de complexidade, mas, sobretudo, pela estrutura peculiar de cada totalidade. (PAULO NETTO, 2011, p. 57. Grifos do autor).

Numa análise da totalidade das peculiares relações do presente que se materializam a partir dos conflitos e da conflitualidade expressa no território Gleba Tauá remetem este a:

[...] descontinuidades; múltiplas variáveis, determinações e relações recíprocas e unidade. É espaço de vida, objetiva e subjetivamente; significa chão, formas espaciais, relações sociais, natureza exterior ao homem; obras e conteúdos. É produto e condição de ações históricas e multiescalares, com desigualdades, diferenças, ritmos e identidade(s). O território é processual e relacional, (i)material. (SAQUET, 2007, p. 73).

O que nos leva a enfatizar aqui uma abordagem (i)material do território (SAQUET, 2007) ao buscamos uma reflexão tanto a respeito do conflito e da conflitualidade materializada na degradação da pessoa e dos empasses em que estes fenômenos se realizam: desapropriação forçada de camponeses por exemplo; à resistência empregada pelas/os posseiras(os) através da luta ao direito pelo território para que assim possam possui-lo com seu trabalho.

O que nos remete a dimensão de território não apenas enquanto:

[...] substrato (palco) ou formas espaciais, nem apenas relações sociais. As próprias relações sociais têm uma (i)materialidade; são objetivas e subjetivas ao mesmo tempo; são plurais e coexistentes, mudam e permanecem, na vida cotidiana. Há uma unidade concreto-abstrata no e do território que precisa ser abstraída. (SAQUET, 2007, p. 73).

Logo coube a nós o engendrar de uma minuciosa análise da "unidade concreto-abstrata" da disputa territorial presente na configuração espacial do espaço geográfico agrário amazônico. Não obstante há emergência de relações conflituosas em que até mesmo pessoas sofrem violências todos os dias no contexto do município de Barra do Ouro-TO.

Com essência expressa na expropriação de posseiras(os) que vivem neste espaço a mais de 60 anos para um exacerbado domínio e expansão do tecnológico modelo monocultor agrícola, o do agronegócio, e seu insaciável plantio de commodities (soja, milho e eucalipto na maioria das vezes) instaurado nas sesmarias do século XXI. Levando-nos a apontar a necessidade urgente da implantação de uma política de revolução agrária no Brasil, para que os camponeses deste país tenham seu acesso à terra livre para desempenhá-lo com seu labor em sua totalidade, como também há não mais omitir-se a existência de um problema social que mata pessoas todos os dias em no país.

\section{MATERIAIS E MÉTODOS}

Por meio de técnicas quantitativas e qualitativas de pesquisa conseguimos recolher relatos e fotos, em entrevistas realizadas a campo, de parte das pessoas que vivem neste lugar (Gleba Tauá) acerca das atuais relações socioespaciais construídas em contexto de conflitualidades que acentuam a violência contra a pessoa no campo tocantinense-brasileiro.

$\mathrm{Na}$ elaboração metodológica, apresenta-se brevemente que - tendo como caminho científico o investigativo e explicativo da totalidade das relações de produção que (re)produzem a sociedade capitalista moderna em que vivemos (MARX, 2008) apropriamo-nos do método de estudo materialista histórico e dialético, com intensão de apreender "a essência (ou seja: a estrutura e a dinâmica) do objeto" (PAULO NETTO, 2011, p. 22), sendo este a conflitualidade territorial desenvolvida a partir do processo de expansão do capital sobre o território da Gleba Tauá. Recriando, na figura do agronegócio, a estrutura do atual modo capitalista de produção em 
contraponto à resistência imposta pela(o) posseira(o) que, na figura de camponês que possui a terra graças aos frutos de seu trabalho, visto nesta pesquisa como o outro $^{2}$, apresenta significante atuação na consolidação das relações que construíram e reconstroem o território aqui estudado.

Estudos possíveis de acesso e compreensão graças aos incansáveis trabalhos da Comissão Pastoral da Terra (CPT), associados a pujantes literaturas sociológicas e geográficas, algumas aqui apresentadas, usadas no entendimento da categoria território (RATZEL apud MORAES, 1990; RAFFESTIN, 1993); da situação de "Fronteira" na Amazônia Legal (MARTINS, 2012); bem como da "conflitualidade territorial da questão agrária" (FERNANDES, 2005) na Gleba Tauá, município de Barra do Ouro-TO. Juntos às leituras apontadas por Haesbaert (2006), a respeito da reterritorialização precária de aglomerados de exclusão no espaço geográfico.

\section{RESULTADOS E DISCUSSÃO}

Fronteira: da (re)territorialização precária do outro em conflitualidade na Gleba Tauá

O norte tocantinense é alvo direto de grande expansão do capital sobre os recursos naturais dando impulso à expropriação camponesa como resultado de tal processo. Caso de estudo a Gleba Tauá aonde posseiros vivem há mais de 60 anos no campo correm risco iminente de desapropriação de seus territórios, localizada no município de Barra do Ouro-TO (conferir figura 1: mapa de localização do município).

Pois aqui territórios se expressam por meio da conflitualidade gerada continuamente pelo desenvolvimento capitalista da questão agrária, à cima de tudo nas relações sociais, onde encontra-se o caso de posseiras(os) que lutam contra o avanço do agronegócio e pelo direito ao território e de empenhar seu trabalho para uso funcional do mesmo nos instigam a indagações de como estruturam-se, nas medidas da conflitualidade, os territórios aqui estudados. Estes, logo adiantando, são resultantes de violência, mas também de resistência como aqui listase.

O município de Barra do Ouro-TO localiza-se a uma latitude $07^{\circ} 41^{\prime 22}$ " Sul e a uma longitude $47^{\circ} 40^{\prime} 58^{\prime \prime}$ Oeste (conferir figura 1), emancipado em 1996 com a Lei Estadual de nº 829, área de 1.106,345 $\mathrm{km}^{2}$, população estimada de 2016 em 4.503 habitantes segundo (IBGE, 2016).

Figura 1. Mapa de Localização do município de Barra do Ouro (Estado do Tocantins).

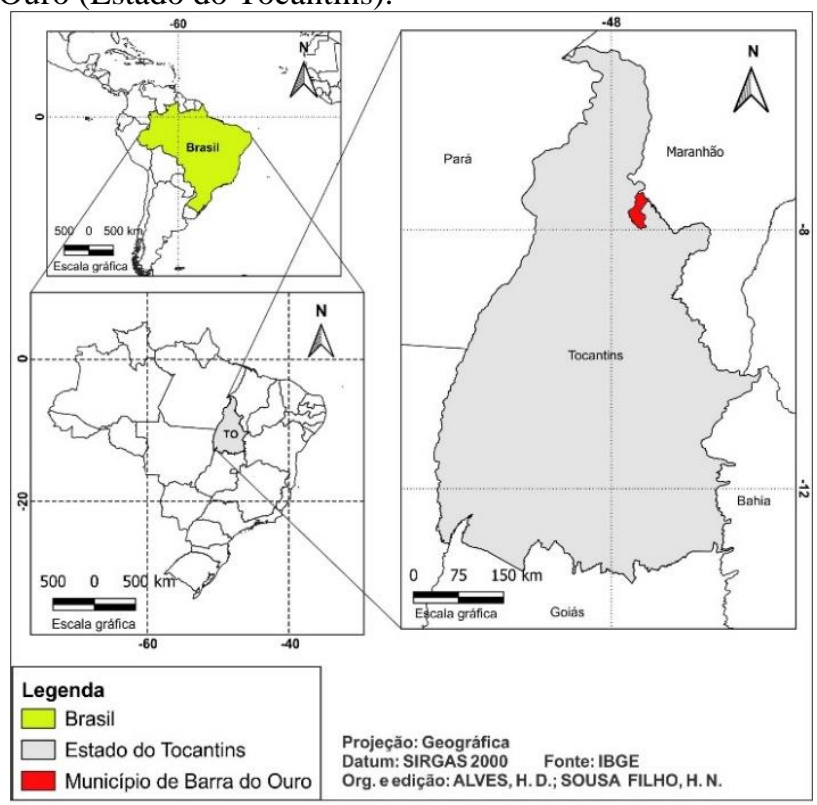

Espaço geográfico de propagação da condição humana de fronteira que, "no âmbito das respectivas concepções do espaço e do homem, a fronteira é, na verdade, ponto limite de territórios que se redefinem continuamente, disputados de diferentes modos por diferentes grupos humanos" (MARTINS, 2012, p. 10).

Os modernos aparatos tecnológicos do atual meio técnico-científico-informacional não são para todas as pessoas e isso nos levou e ainda leva a uma concepção de que a territorialização do capital (re)configura continuamente o espaço geográfico correspondente à Gleba Tauá ao fazer com que posseiras(os) camponeses (re)territorializem-se, uma 
vez expropriados de seus tradicionais territórios por suas culturas não corresponderem as demandas do "livre" mercado, de forma precária no espaço agrário tocantinense.

Consoante, a (re)territorialização precária do outro aqui é marcada por este não está inserido no movimento que (re)cria os novos "territórios-rede" globalizados pelo sistema técnico da informação (HAESBAERT, 2006) que se instala no campo brasileiro através das modernas práticas trazidas pela revolução verde.

Assim, quando tratamos da conflitualidade para análise material-relacional pretendida ao território em estudo,

[...] sem ignorar a força de fatores de ordem cultural, enfatizaremos aqui a dimensão socioeconômica das dinâmicas de exclusão, pelo simples fato de que é ela quem responde melhor, hoje, pela formação daquilo que estamos denominando "aglomerados" e processos de "territorialização precária" ou/e reterritorialização precária do outro. (HAESBAERT, 2006, p. 319. Grifos nossos acrescentados em itálico).

As diferentes formas técnicas presentes na (re)construção histórica da Gleba Tauá se cruzam no estado de fronteira que discutimos e continuaremos a discutir na medida em que tentamos compreender o desencontro dos diferentes modos de produção funcional do território mediante a "convivência de diversos modos de existência técnica, que coexistem e se afrontam, cada qual com suas próprias" (SANTOS, 2017 , p. 180) formas de uso da terra.

$\mathrm{O}$ que nos traz olhares remetentes dá conflitualidade existente na descontinuidade dos modos de vida e concepções de futuro responsáveis por formular o estado, material e simbólico como referenciamos, de fronteira da alteridade.

Desse modo,

[...] a fronteira no Brasil é, justamente, a situação de conflito social. [...] nesse conflito, a fronteira é essencialmente o lugar da alteridade. É isso que faz dela uma realidade singular. [...] o conflito faz com que a fronteira seja essencialmente, a um só tempo, um lugar de descoberta do outro e de desencontro. Não só o desencontro e o conflito decorrentes das diferentes concepções de vida e visões de mundo de cada um desses grupos humanos. $\mathrm{O}$ desencontro na fronteira é o desencontro de temporalidades históricas, pois cada um desses grupos está situado diversamente no tempo da história. (MARTINS, 2012, p. 133).

Na Gleba Tauá este desencontro acentua-se devido desenfreada e destrutiva expansão do modo de produção de lógica capitalista sobre as paisagens da região abraçada em sua totalidade pelo projeto político-econômico MATOPIBA, caracterizado conceitualmente como:

[...] uma nova (velha) ampliação dos conflitos no campo, com maiores investimentos na produção de commodities. [...] um projeto que compromete o bem viver ancestral e causa consequências nefastas na vida dos/das camponeses/as e dos povos tradicionais. (SILVA JUNIOR; WICHINIESKI; COSTA, 2015, p. 158).

Referindo-se ao espaço geográfico agrário tocantinense na "era da 'globalização' do capital” (MASSEY, 2017, p. 229) como problemática contextual aqui defendida numa leitura do estado de fronteira (degradação) do outro, situada no território Gleba-Tauá, é importante frisar que empregamos uma leitura funcional do território que para os latifundiários produtores de soja presentes na região seu uso deve ser funcionalmente desenvolvido num olhar deste como recurso único e exclusivo de geração de renda, para uma maior hegemonia. Enquanto que os hegemonizados, aqui posseiras(os), fazem uso do território quanto abrigo para plenitude e sobrevivência de seus iguais (conforme figura 2). 
Figura 2. Apropriação sustentável do espaço geográfico pelo posseiro da Gleba Tauá, localizada no município de Barra do Ouro (Estado do Tocantins).

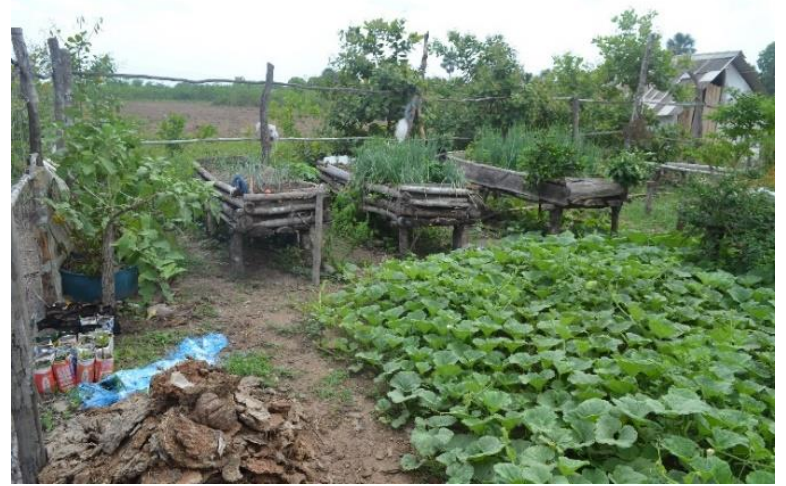

Fonte: SOUSA FILHO. Setembro de 2018.

É o que ressalta Milton Santos (2000) defendendo a ideia do território usado por atores hegemônicos e hegemonizados. Capitalistas em disputa com proletários, entre patrões e empregados, latifundiários e posseiros - a contrapartida da luta pela terra que camponeses empregam a todo momento para defender seus direitos aos territórios frente àqueles que os invadem para gerar cada vez mais e mais recursos e riquezas a partir da desumana expropriações de famílias tradicionais em nome de acumulo de capital.

Assim, conforme ressalta Milton Santos:

Para os atores hegemônicos o território usado é um recurso, garantia da realização de seus interesses particulares. Desse modo, o rebatimento de suas ações conduz a uma constante adaptação de seu uso, com adição de uma materialidade funcional ao exercício das atividades exógenas ao lugar, aprofundando a divisão social e territorial do trabalho, mediante a seletividade dos investimentos econômicos que gera um uso corporativo do território. Por outro lado, as situações resultantes nos possibilitam, a cada momento, entender que se faz mister considerar o comportamento de todos os homens, instituições, capitais e firmas. Os distintos atores não possuem o mesmo poder de comando levando a uma multiplicidade de ações, fruto do convívio dos atores hegemônicos com os hegemonizados. Dessa combinação temos o arranjo singular dos lugares. [...] Os atores hegemonizados têm o território como um abrigo, buscando constantemente se adaptar ao meio geográfico local, ao mesmo tempo que recriam estratégias que garantam sua sobrevivência nos lugares. É neste jogo dialético que podemos recuperar a totalidade. (SANTOS, 2000, p. 108).
Para o uso do território quanto recurso os atores hegemônicos se apropriam de todo um suporte técnico-científico-informacional global para realizar suas particularidades de forma acelerada, destrutiva e desigual (conforme figura 3); enquanto que as(os) posseiras(os) da Gleba Tauá usam este mesmo território como abrigo para tentarem sobreviver a partir do emprego de suas tradicionais culturas, com ações tidas hegemonizadas. E é exatamente nesta história, ou melhor, contexto histórico de contrapontos que a fronteira materializa-se pelo confronto de diferentes formas técnicas de produção funcional dos territórios em apropriação do espaço geográfico agrário.

Figura 3. Apropriação tecnológica e destrutiva do espaço geográfico pelos fazendeiros latifundiários que invadem os territórios tradicionais da Gleba Tauá - localizada no município de Barra do Ouro (Estado do Tocantins) -, com produção de monocultura de soja.

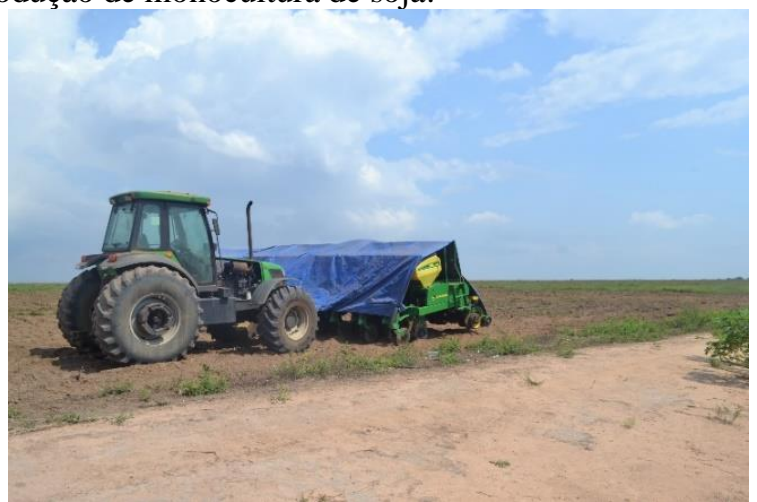

Fonte: SOUSA FILHO. Setembro de 2018.

No caso das(os) posseiras(os) na Gleba Tauá, exemplificando melhor o processo até então apresentado como (re)territorialização precária de aglomerados de exclusão, é dizer que esse fenômeno não entende-se apenas como a perca dos territórios tradicionais de suas vidas camponesas como o fato de não viverem mais um estado ancestral de bem viver reciproco com a terra-natureza. Mas de encontraremse hoje em um contexto fragilizado e conflituoso, estado de propagação da violência, sobretudo do corpo que sobreveio com a territorialização do capital na região; responsável por mudar bruscamente a vida de 
pessoas aglomerando-as em estado de exclusões (o que pode ser vislumbrado na figura 4)... Antes de tudo dos seus direitos básicos fundamentais.

Figura 4. Morada de posseira na Gleba Tauá, localizada no município de Barra do Ouro (Estado do Tocantins).

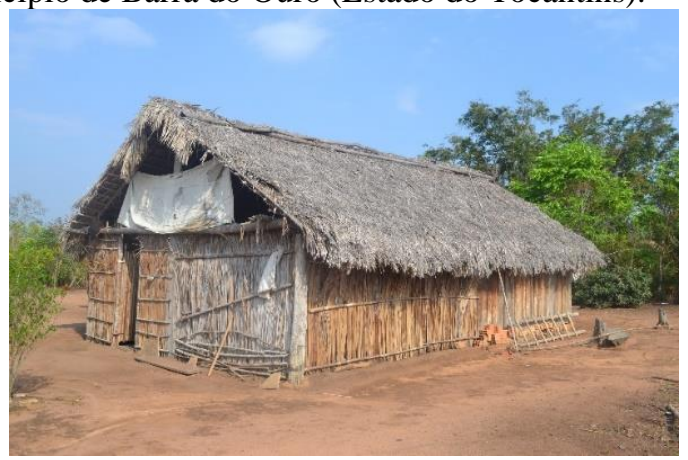

Fonte: SOUSA FILHO. Setembro de 2018.

Haesbaert (2006) salienta que a "perca" de territórios, ou o "fim" como prefere alguns, não mais se faz compreendida apenas como desterritorialização pois, se a fluidez em redes hoje promove uma maior velocidade comunicacional e tecnológica de informações - também no campo - o que ocorre logo não se trata de "perca" ou "fim" das antigas (originais/tradicionais) organizações territoriais; mas de uma constate dinâmica voltada à vivência e experimentação de múltiplos territórios em instantâneos momentos. $\mathrm{O}$ que nos insere em multiterritorialidade: viver, em poucos segundos, da mais tradicional e "rustica" à mais "sofisticada" e tecnológica forma técnica de construção histórica de nossa sociedade.

Ainda para Haesbaert:

[..] É como se a crescente desterritorialização/exclusão, gerando novos "aglomerados", tivesse seu contraponto no reforço de uma territorialização também excludente, mas comandada agora pelos grupos que se sentem "ameaçados" pela massa excludente de excluídos pela qual, em grande parte, também são responsáveis. (2006, p. 321-322).

O que acontece também com o campesinato tocantinense - e não mais falando apenas das posseiras e posseiros de Barra do Ouro-TO mas dando ênfase aos quilombolas, indígenas, quebradeiras de coco babaçu, ribeirinhos e todas as pessoas, povos e comunidades que sofrem com a luta incessante pelo direito à terra e da permanência de seus territórios que hoje estão imersos em situação social de fronteira que está tendo suas culturas expropriadas de seus territórios sob essa onda de modernização do espaço agrário do Tocantins com forte lógica de cunho lucrativo. Impondo como ideologia (ideia) dominante aquela que visa sempre às vantagens propostas pela tecnologia para sempre obter maior produção exportadora que exclui e massacra o modo familiar de produção com suas armas químicas diariamente.

Segundo Mitidiero Junior (2016, p. 33), ao tratar os aspectos da dinâmica de territorialização do capital no campo, é necessário compreender que:

[...] a expansão do capitalismo no campo não sofre retrações como reflexo direto da crise, mas sim, amplia-se a exploração da natureza (terra, subsolo, água, petróleo, ar, energia solar etc.) que tem nas áreas rurais o seu âmago. [...] o Estado capitalista, sempre subserviente aos ditamos do capital, se coloca de forma múltipla, ora garantindo a partir de sua institucionalidade os mandos e desmandos do capital, ora fazendo vistas grossas à usurpação dos bens naturais coletivos por esse capital sem pátria e sem alma.

A conflitualidade, diferentemente do conflito por ser uma oposição política e econômica muito momentânea, "é um processo constante alimentado pelas contradições do capitalismo" (FERNANDES, 2005, p. 2). É movimento de destruição e recriação de relações sociais possíveis de análises nas suas temporalidades e espacialidades - sendo continuamente gerada pela questão agrária advinda "da contradição estrutural do capitalismo que produz simultaneamente a concentração da riqueza e a expansão da pobreza e da miséria" (FERNANDES, 2005, p. 4).

A conflitualidade e o desenvolvimento acontecem simultâneos e consequentemente, promovendo a transformação de territórios, modificando paisagens, criando comunidades, empresas, municípios, mudando sistemas agrários e bases técnicas, complementando mercados, fazendo 
costumes e culturas, reinventando modos de vida, reeditando permanentemente o mapa da geografia agrária, reelaborado por diferentes modelos de desenvolvimento. (FERNANDES, 2005, p. 6).

Na disputa de territórios para consolidação de culturas por distintas concepções de destino, acentua Martins (2012), apontamos o capital significado na figura do agronegócio em um constante avanço da frente pioneira vista como a fronteira econômica (MARTINS, 2012) que invade os territórios de posseiras(os) - " aquele que possuindo a terra, não tem seu domínio" (FERNANDES, 2001, p. 2) pois a posse pela terra se dá pelo fruto de seu trabalho - com apoio acima de tudo da mídia que constrói apologias para blindar o agronegócio ao ponto de separá-lo da conflitualidade ocorrida no espaço agrário (FERNANDES, 2005).

$\mathrm{O}$ discurso que se prega na sociedade, inclusive nos meios midiáticos, é o de um capital econômico compromissado com a produtividade para cumprir sua função social na terra, pois o agro é pop, é tech é tudo. Logo percebemos que o agronegócio amplia seus territórios - com apoio do Poder constitucional e de parte da população desinformada pelo estado de propósito - na camuflagem de sua conflitualidade. Esta mascara está empregada na imagem do agronegócio como "espaço produtivo por excelência, cuja supremacia não pode ser ameaçada pela ocupação de terra" (FERNANDES, 2005, p. 38). Dando grande repercussão e legitimidade à criminalização da luta pela terra via mecanismos públicos institucionais.

Nesta disputa guiada por desencontros apontamos uma noção de "poder", e outra de "Poder" (RAFFESTIN, 1993), que, de forma relacional, expressam-se no espaço geográfico pelas relações sociais instituídas entre pessoas e entre estas e o setor empresarial privado (poder), e entre estes agentes em sujeição ao Estado (Poder), respectivamente. Todavia, a lógica geral citada nestas relações é consolidada pela noção de riqueza sob acúmulo de capital e também na acumulação de terras para formação de latifúndios. Uma vez que as relações de poder ao domínio do capital promovem certa ampliação da conflitualidade, pois diante dos "limites de acumulação, é bem provável que o capital tente ampliar, a qualquer custo, o seu poder de domínio de todas as esferas da vida social” (MITIDIERO JUNIOR, 2016, p. 21).

É nessas esferas que apreendemos a estruturação da conflitualidade territorial na Gleba Tauá

relacionada, essencialmente, à propriedade da terra, à renda da terra, à reprodução capitalista do capital, consequentemente à concentração da estrutura fundiária e aos processos de expropriação dos camponeses e assalariados por diversos meios e escalas e bases sociais, técnica econômica e política. (FERNANDES, 2005, p. 27).

Nessa perspectiva apontamos exacerbada expansão do modo de produção capitalista sobre os territórios das(os) posseiras(os) viventes na Gleba Tauá. É que não se faz aceitável a rentabilidade de excedentes da produção camponesa ao invés de uma rentabilidade em grande escala produtiva, ainda mais de interesse de exportação. Por isso frisamos que a conflitualidade territorial criada pela questão agrária construída neste espaço nos remete a refletir sobre um embate onde grandes empresas, amparadas pelas políticas econômicas governamentais ora com apoio de mecanismos opressores do governo, promovem a expulsão de camponeses para implantação, na maioria das vezes, de monoculturas objetivadas na geração pura e simples de acúmulo de capital. Sobrepondo técnicas modernas de mecanização do campo às tradicionais culturas dos povos que vivem e resistem no Tocantins.

\section{CONCLUSÃO}

Para não concluir, analisamos que a conflitualidade na Gleba Tauá, em Barra do Ouro-TO, 
região norte do Tocantins, a respeito da expulsão de posseiras(os) que vivem há mais de 60 anos para ocupar os grileiros produtores de soja tem sua totalidade expressa na resistência destes povos tradicionais à expansão hegemônica do agrário. Que, a partir de sua territorialização, reterritorializa de forma precária as famílias que vivem sob as ameaças e até mesmo despejos por meio dos que trabalham para os donos do agronegócio. Camponeses viventes sob modo reciproco para com a terra e que resistem as violências de lógica capitalista através da prática familiar agrícola.

Pois, no contexto analisado a partir do espaço agrário tocantinense criado pelo conflito histórico entre a relação de diferentes técnicas de uso do território - logo sendo uma fronteira da alteridade marcada pelo confronto entre/de diferentes modos de vida e concepções de relação territorial com espaço geográfico agrário de Amazônia Legal. Distintamente dos "grandes" empresários do agronegócio que fazem uso da terra e produzem práticas agroindustriais com todo um conjunto de modernos aparatos tecnológicos como insumos químicos, grandes maquinários que substituem os serviços braçais como de plantio e colheita e até mesmo sementes geneticamente modificadas contrapõem-se a/o posseira(o) camponês que resiste mediante o emprego de suas culturas e na defesa incessante de seus tradicionais territórios.

\section{AGRADECIMENTOS}

O presente trabalho foi realizado com o apoio do Conselho Nacional de Desenvolvimento Científico e Tecnológico - CNPq - Brasil, meus cumprimentos; Ao meu orientador, Alberto Pereira Lopes, por segurar em minha mão sabendo me amparar nos momentos complexos em que vivemos no espaço do saber científico;
Às minhas mães, Rosângela Melo da Silva e Vera Lúcia da Silva Maia, por encontrarem-se sempre presentes ao meu lado durante os momentos felizes e infelizes de minha vida;

À minha filha, Catarina Paiva Nascimento, por ser minha inspiração e refúgio de amor;

Especialmente aos moradores posseiros da Gleba Tauá pelo enorme apoio e incalculáveis colaborações para com a realização desta pesquisa.

Todos os autores declararam não haver qualquer potencial conflito de interesses referente a este artigo.

\section{NOTAS}

1 - Cf. Araguaína Notícias (27/07/2018): "Pistoleiros derrubam barraco de camponeses na Gleba Tauá, em Barra do Ouro". Disponível em: http://araguainanoticias.com.br/noticia/45926/pistolei ros-derrubam-barraco-de-camponeses-na-gleba-dotaua-em-barra-do-ouro/. Acesso em: 27/07/2018.

2 - Presente do lado de "cá", o outro é visto como não civilizado pelos que estão do lado de "lá" da fronteira. (MARTINS, 2012).

3 - Em J. S. Martins (2012) é possível um diálogo caloroso para caminhar a um entendimento da produção da dual situação de fronteira a começar pela econômica, mas sobretudo a situação de fronteira da alteridade; de degradação e mutilação de diferentes modos de vida que "no âmbito das respectivas concepções do espaço e do homem, a fronteira é, na verdade, ponto limite de territórios que se redefinem continuamente, disputados de diferentes modos por diferentes grupos humanos" (MARTINS, 2012, p. 10). 4 - Devido seu sentido polissêmico alguns ainda adotam a visão pela Geografia critica. Cf. Haesbaert (2006).

\section{REFERÊNCIAS}

CABRAL, D. D. R. Tem cheiro de sangue na terra camponeses brasileiros entre a violência e a injustiça. In: CANUTO, Antônio; SILVA LUZ, Cássia Regina da; ANDRADE, Thiago Valentim Pinto (Coord.). 
Conflitos no Campo - Brasil 2015. Goiânia: CPT Nacional, 2015. p. 144-150.

CAVALCANTE, M. E. S. R. Tocantins: o movimento separatista do norte de Goiás. São Paulo: A. Garibaldi, Editora da UCG, 1999.

FELICIANO, C. A. A prática da violência no campo brasileiro do século XXI. In: Eraldo da Silva Ramos Filho; Marco Antonio Mitidiero Junior; Laiany Rose Souza Santos. (Org.). Questão Agraria e Conflitos Territoriais. $1^{a}$ ed. São Paulo: Outras Expressões, 2016, p. 81-100.

FERNANDES, B. M. Questão agrária: conflitualidade e desenvolvimento territorial. In: BUAINAIN, A. M. (Ed). Luta pela terra, reforma e gestão de conflitos no Brasil. Campinas: Ed. UNICAMP, 2005.

FERNANDES, B. M. Brasil: 500 anos de luta pela terra. Revista de Cultura Vozes, Março de 2001. Disponível em: www.culturavozes.com.br/revistas/0293.html.

FIRPO PORTO, M.; ROCHA, D. F.; PACHECO, T. Agrotóxicos, armas de uma guerra não declarada. In: CANUTO, A.; SILVA LUZ, C. R.; ANDRADE, T. V. P. (Coord.). Conflitos no Campo - Brasil 2015. Goiânia: CPT Nacional, 2015. p. 133-141.

FOUCAULT, M. Sobre a geografia. In: Microfísica do poder. $18^{\circ}$ ed. Rio de Janeiro: Graal, 2003, p. 153-165.

GONÇALVES, C. W. P. Geografia da Violência contra a Pessoa no Campo Brasileiro: agronegócio, grilagem e devastação. In: Conflitos no Campo Brasil 2004. (Coord.: Antônio Canuto, Cássia Regina da Silva Luz e José Batista Gonçalves). Goiânia: Comissão Pastoral da Terra, 2004, p. 142-156.

HAESBAERT, R. O mito da desterritorialização: do "fim dos territórios" à multiterritorialidade. 2. ed. Rio de Janeiro: Bertrand Brasil, 2006.

MARTINS, J. S. Fronteira: a degradação do Outro nos confins do humano. $2^{\mathrm{a}}$ ed. São Paulo: Contexto, 2012.

MARX, K. Contribuição à crítica da economia política. Tradução: Florestan Fernandes. São Paulo: Expressão Popular, 2008.

MASSEY, D. Globalização: o que significa para a geografia?. Boletim Campineiro de Geografia, v. 7, n. 1, p. 227-235, 2017.
MITIDIERO JUNIOR, M. A. Crise do Capital Global, Natureza e Agronegócio. In: Eraldo da Silva Ramos Filho; Marco Antonio Mitidiero Junior; Laiany Rose Souza Santos. (Org.). Questão Agrária e Conflitos Territoriais. $1^{\mathrm{a}}$ ed. São Paulo: Outras Expressões, 2016, p. 17-36.

PAULO NETTO, José. Introdução ao estudo do método de Marx. São Paulo: Expressão Popular, 2011.

PIETRAFESA, José Paulo. Conflitos agrários, protagonismo camponês e ocupações de terra no Brasil. In: CANUTO, Antônio; SILVA LUZ, Cássia Regina da; ANDRADE, Thiago Valentim Pinto (Coord.). Conflitos no Campo - Brasil 2015. Goiânia: CPT Nacional, 2015. p. 100-108.

RAFFESTIN, Claude. Por uma Geografia do poder. Tradução: Maria Cecília França. São Paulo: Editora Ática, 1993.

RATZEL, F. Geografia do homem (antropogeografia). In: MORAES, Antonio Carlos Robert. Ratzel: Geografia. São Paulo: Editora Ática, 1990, p. 32-107.

SABOURIN, Eric. Camponeses do Brasil: entre a troca mercantil e a reciprocidade. Rio de janeiro: Garamond, 2009.

SANTOS, M. A Natureza do Espaço: Técnica e Tempo, Razão e Emoção. $4^{\circ}$ ed. São Paulo: Editora da Universidade de São Paulo, 2017.

O papel ativo da Geografia: um manifesto. Revista território, Rio de Janeiro, ano V, nº 9, p. 103109, jul./dez., 2000.

SAQUET, M. A. As diferentes abordagens do território e a apreensão do movimento e da (i)materialidade. Geosul, v.22, n.43, p. 55-71, 2007.

SAUER, Sérgio. Terra e modernidade: a reinvenção do campo brasileiro. São Paulo: Expressão popular, 2010 .

SILVA JUNIOR, Jose Plácido; WICHINIESKI, Isolete; COSTA, Saulo Barros da. A pílula dourada do agrohidronegócio, o MATOPIBA. In: CANUTO, Antônio; SILVA LUZ, Cássia Regina da; ANDRADE, Thiago Valentim Pinto (Coord.). Conflitos no Campo - Brasil 2015. Goiânia: CPT Nacional, 2015. p. 153158. 